councils should not merely be allowed but compelled to publish their arguments. If doing this should run counter tr what the constitution says, then somebody should rechristen the committees.

The second issue is the course which the British Government should pursue towards the CERN proposals. The hiatus which has now arisen stems from devaluation and from the need for a further examination of plans at CERN. It is a welcome respite, but it will not last for ever. The chief conclusion of the documents which have now been published in Britain will most probably still be valid for most of the year ahead. In other words, it will probably be sensible that the British Government should participate. But there are grounds for asking that plans for the new machine should be more open-ended.

\section{Hovercraft at Bay}

Pegwell Bay, in Kent, is to be the site of a British hoverport. After a year's delay and a second session of public inquiry the Minister of Housing, Mr Anthony Greenwood, has granted planning permission for Hoverlloyd to build their hoverport, which is likely to cost nearly $\& 1$ million. Detailed plans of the scheme have also to be passed by the minister, as he is anxious to preserve as much as possible of the wild life of the bay. It has also been stipulated that no development can occur within 20 feet of the upper edge of the cliff, so that the geological features of the cliff will remain accessible. A fixed flight path has been approved for the hovercraft so that disturbance to bird life will be kept to a minimum. Dr Peter Gay, regional officer of the Nature Conservancy, thinks that about a quarter of the bay will be taken over from the birds, which include waders and wildfowl. The bay is an important feeding and resting ground for migrants, and a breeding ground for little terns which are becoming less common elsewhere. The flight path is to pass at least half a mile north of the breeding grounds at Shell Ness.

Hoverlloyd's first SR.N4 is due to be completed in the spring. Extensive sea trials will be required before a licence for operations can be granted by the Board of Trade, but it is hoped that the craft will be ready for service by the end of the year. A second craft should be ready in time for a full cross-Channel service to be operated in the spring of 1969 .

Hoverlloyd originally suggested using Ramsgate
Whatever arrangements may now be made, however, they are likely only to be temporary. It is not too soon for governments to be thinking of the next machine. There is no assurance at this stage that reason will persuade all nations with an interest in high energy physics that a thoroughly international version of CERN would be the best solution. If there is a chance that super-conducting magnets or some other technical innovation could contain the cost of building more powerful machines, the United States and the Soviet Union might well elect to go ahead independently. In the circumstances, the greatest need is to ensure the closest co-operation within the members of CERN not merely on the building of big machines but in the less spectacular parts of high energy physics as well.

harbour for their depot, but the entrance was thought to be too narrow for safe manoeuvring, particularly in rough weather. Pegwell Bay was then suggested, as having the best conditions for a hoverport. Planning permission was requested and a public inquiry was opened in January a year ago. The inspector's resulting report recommended that the application be granted, although it was thought the whole question of hovercraft travel should be examined within the context of a national transport policy. Following the announcement that British Rail was planning to run a hovercraft service from inside Dover harbour, the minister decided to reopen the public inquiry, to hear the relative merits of Dover against those of Pegwell Bay. It was found that in bad weather British Rail would be able to use their boats as an alternative service. Hoverlloyd, on the other hand, will operate hovercraft only. They will not be able to make a switch, and will therefore require an open site for their operations. The second inspector's report reinforced the view of the first, and, taking into account the effect of hovercraft on the national economy with particular reference to export potential, the minister has finally granted the required permission.

The new planning Bill, which is at present before Parliament, should prevent delays like this occurring again, as a preliminary inquiry should consider any possible sites. Further alternatives will therefore not arise after the public inquiry has taken place, as has been the case with the hoverport.

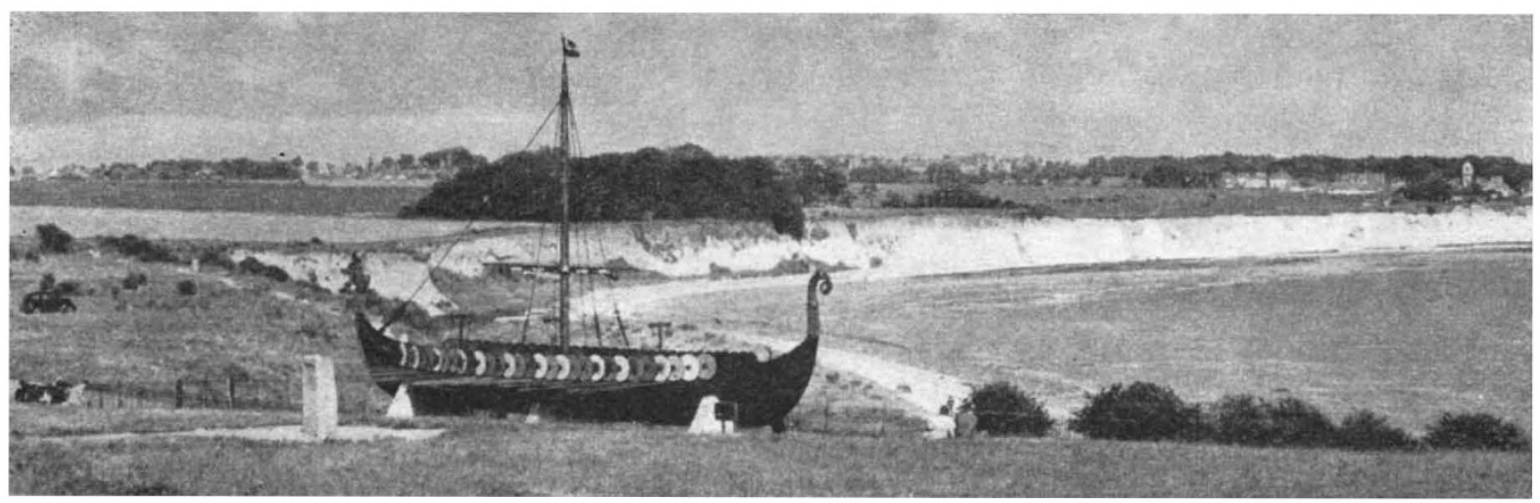

Pegwell Bay in Kent; future arrivals will be made by hovercraft. 